\title{
Theory of Constraints in Construction Projects
}

\author{
Mustafa Hassan Talib \\ Civil Engineering Department Engineering \\ Projects Management, University of \\ Technology, Baghdad, Iraq \\ 42125@student.uotechnology.edu.iq
}

\author{
Afrah Mohammed Hassan Kashkol \\ Civil engineering Department, University of \\ Technology, Baghdad, Iraq \\ 40182@uotechnology.edu.iq
}

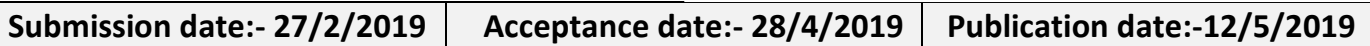

\begin{abstract}
:
Construction projects in Iraq are suffering from constraints (financial, technical, political, legal and environmental) that hamper their work. It is therefore necessary to identify these constraints by following the theories in order to accurately identify and provide useful information to make decisions about production constraints and their impact on work. To achieve its objectives or achieve a level of performance for this goal, so it is necessary to use some theories, including theories of constraints that identify those obstacles and find solutions to those obstacles through the schemes of thinking. The concept of constraints is defined as "a comprehensive management philosophy that aims to achieve a continuous achievement of more than one goal in a project." If the project works to achieve a certain achievement in a project after defining the constraints and types and each according to its importance and impact, Which provides a comprehensive framework for the work of projects, as it helps to identify and treat the obstacles experienced by the projects and work to identify appropriate solutions and through a set of logical thinking throughput that begin studying the current reality of the project that suffers from the obstacles and then search for Constraints A number of proposed solutions are then presented. These solutions are examined and the future results of each solution are identified and useful in addressing the specific problem and the extent of the future impact of its application. The methodology used in the research of extracting indicators from the theoretical and practical framework and finding solutions through the curriculum of the thinking throughput will be used to reach a number of conclusions and recommendations aimed at achieving its objectives
\end{abstract}

Keywords: Constraint, Theory of constraints, Thinking throughput. 


\section{نظرية القيود في المشاريع الانشائية}

\author{
مصطفى حسن طلب \\ قسم الهندسة المدنية، دارة مشاريع هندسية، الجامعة

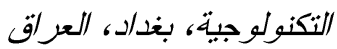

42125@student.uotechnology.edu.iq
افراح محمد حسن كشكول

قسم الهندسة المدنية، الجامعة النكنولوجية، بغد/د، العراق

40182@uotechnology.edu.iq

\section{الخلاصة}

تعاني المشاريع الانثائية في العر اق من القيود (الاقتصادية و النقبية و السياسية والقانونية و البيئية) التي تعوق عملها لذا مسن

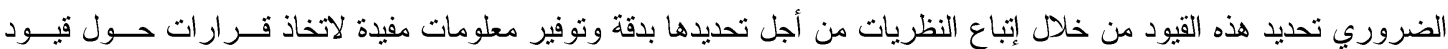
الإنتاج وتأثيرها على العمل، يعرف القيد بأنه: أي محدد يمنع المشروع من تحقيق أهدافه أو تحقيق مستوى من الأداء بالنسبة لهــا الهدف، لذا لا بد من استخدام بعض النظريات، بما في ذلك نظريات القيود التي تحدد لها وإيجاد حلول لتلك العقبـات مسن خــال

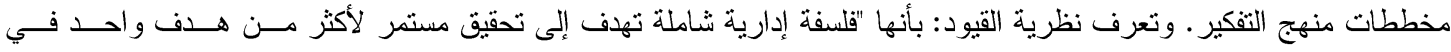

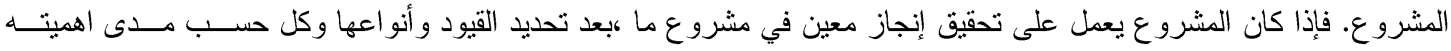
وتأثنيره سوف يتم ايجاد الحلول لها بواسطة "منهج ألنفكير" الذي يعرف بأنه : يوفر اطار متكامل لإلية عمل المشاريع اذ بساعد على تحديد ومعالجة المعوقات التي تعاني منها المشاريع و العمل على تحديد الحلول الملائمة وذلك من خلال مجموعة مـن مخططـات

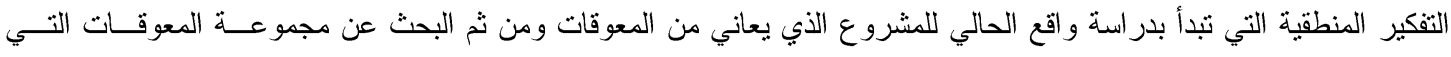
تعانيها ويتم ترتيب المعوقات بحسب اهميتها ومدى ارتباطها ببعض وذلك من أجل تحديد المشاكل الجوهرية التي تسبب في حسدوث

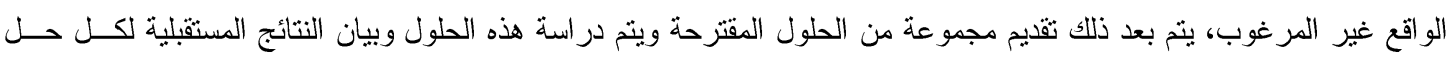

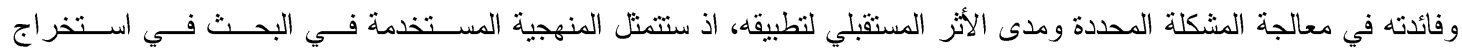

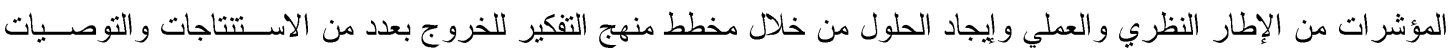
الر امية إلى تحقيق أهداف البحث. الكلمات الداله: القيد، نظرية القيود، منهج التفكير. المشكلة :أصبحت المشاريع الإثثائية تعاني من معوقات (اقتصادية وفنية وسياسية وقانونية وبيئية) تعرقل سير عملها لذا لا بد من

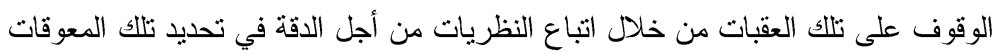

الفرضية: تتلذص في اختبار أفضل الحلول على البعدين التخطيطي و التتفيذي والتي تتبلور في دراسة أحدث الامكانيات بإتباع مبدأ

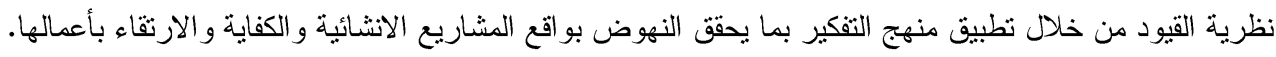

الهدف: بيان المعوقات ومعالجة القيود التي تعاني منها الثركات الانثائية وكنلك بيان أهمية نظرية القيود في توفير أسلوب علمي

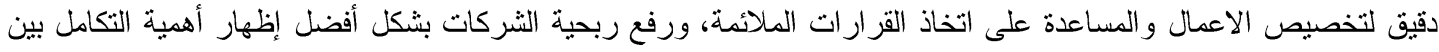
المعوقات ونظرية القيود في رفع مسنوى أداء المشاريع وتعزيز وضعها.

تمهيد: ازداد دور الحكومات في الكثير من دول العالم النامي بعد الحرب العالمية الثانية في مجال تجهيز السكان بالخدمات المحليــة

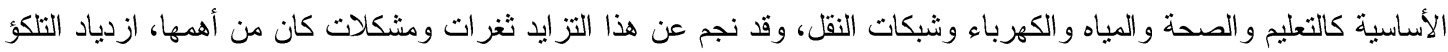

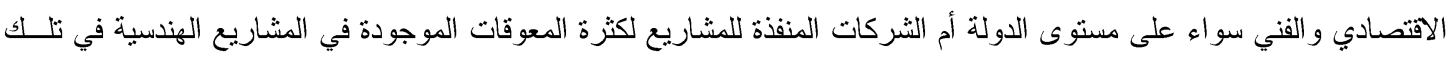

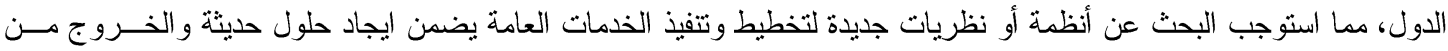




\section{1.نظرية القيود}

هي فلسفه ادارية شاملة تهدف الى التحقيق المستمر لأكثر من هدف في المشروع اي إذا كانت أعمال المشاريع تهدف إلـى

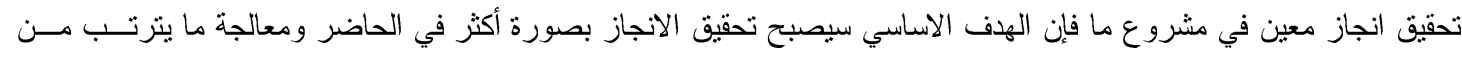

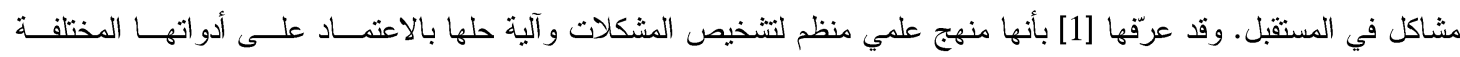
و عرقّها [2] بأنها فلسفة ادارية تعكس أساسا" مناسبا" لاتخاذ القرارات الخاصة بتحديد القيد أو مجموعة القيود وكيفية ادارتها بكفــاءة وفعالية وذلك بهدف التحسين الفعال لعو امل النجاح الجوهرية للمشاريع لتعظيم الاثشطة لها ومن ثم تحقيق الاهــــاف الاســتر اتيجية

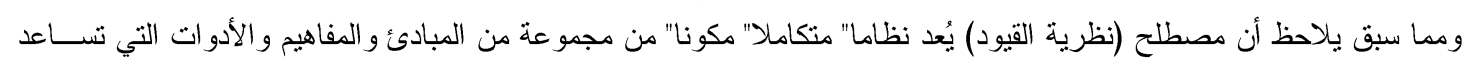

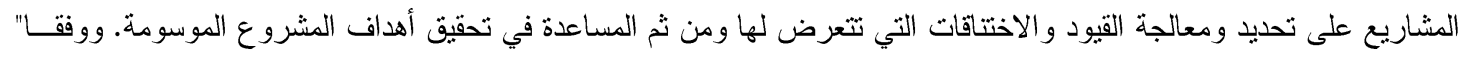

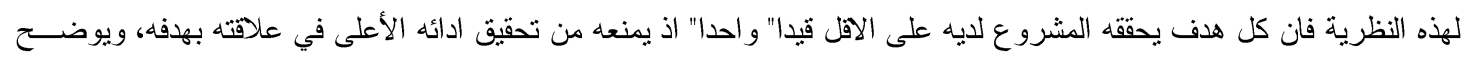

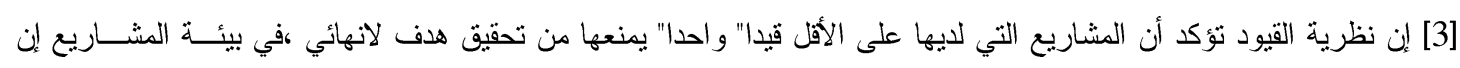

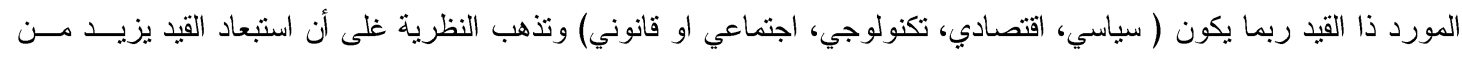

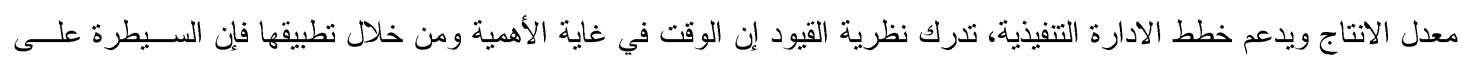
القيود يهدف إلى تحقيق إنتاج أكثر من فقرات الادة المشروع

1-1 أهمية نظرية القيود:

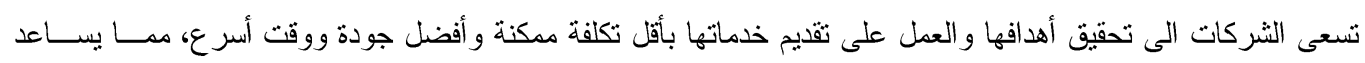

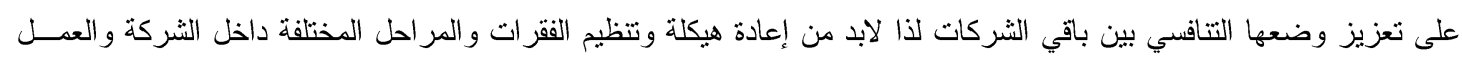
على التخلص من اب معوقات وقيود تحد من قدرتها على تحقيق ذلك، وهذا ما ينطبق مع فلسفة نظرية القيود التي تهدف الى الحــد

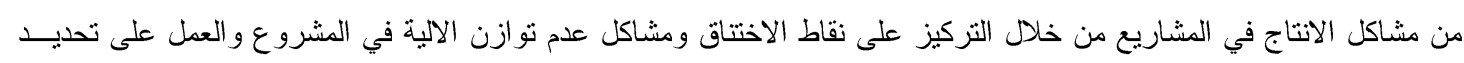

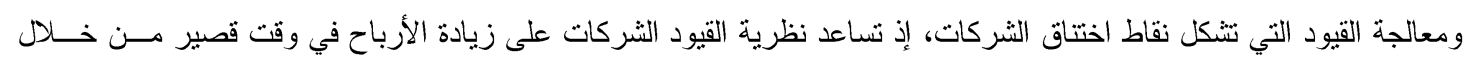

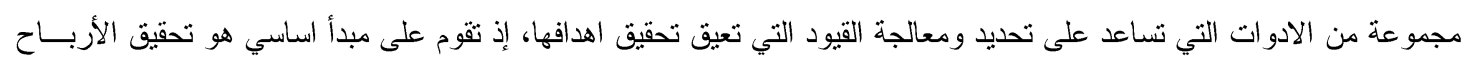

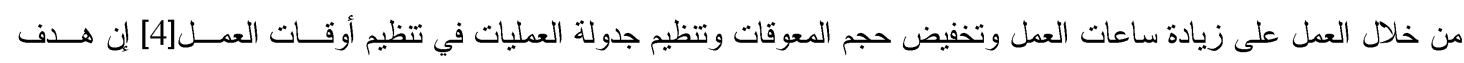

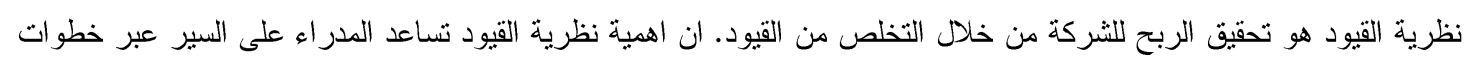
منطقية للتدفق عبر العملية إذ تسعى إلى:

1.تحقيق القبول الو اسع للمشكلة.

2. تحقيق القبول الواسع على الاتجاه نحو الحل المقترح.

3. تحقيق القبول الواسع بان الحل المقترح سيكون كافيا للتغلب على المشكلة.

4.المو افقة على التغلب على أبي تشعبات سلبية محتملة.

5.المو افقة على التغلب على أي عقبات عند التطبيق.

1-2 فو ائد نظرية القيود:

لنظرية القيود العديد من الفو ائد والتي تعود على الثركات من جر اء تطبيقها منها:

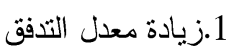

ويتم ذلك باستبعاد معظم القيود الجوهرية، اذ تكون الثركات قادرة على توليد الإير ادات عالية من طريق انتاج أعلى من

الفقر ات الخاصة بالمشروع.

2.تخفيض كلفة الانتاج: 


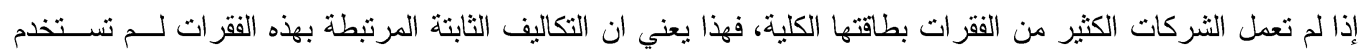

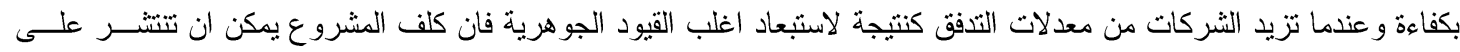

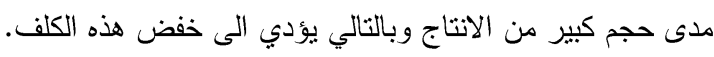
3.التسليم في الوقت المحدد:

في اغلب الاحيان إذا كان جزء من الثركة يقع تحت بعض القيود الجوهرية و التي ليست تحت الرقابــة كبــــي الفقـرات داخل الثركة، كنتيجة لذلك فان القيد نفسه او زيادة التدفق ترجع الى زيادة الانتاج في الفقرات من هذا القيد القيد. 4.تخصيص وقت الادارة بالطريقة التي تحقق عو ائد اعلى: من خلال التركيز على معظم القيود الجوهرية فأن وقت الادارة سوف يتم تخصيصه لحل المشكلات التي تحدث و التي قــــ

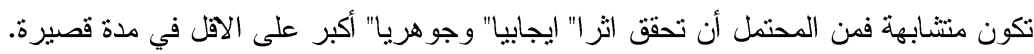
5.تحسين نو عية العمل.

6. الاستغلال الامثل للقيد وتحسينه.

يتيين مما سبق إن نظرية القيود نتكل اطار ا" منكاملا" يخدم مختلف مجالات عمل الثركة من خلال ما توفره من منهجيـة

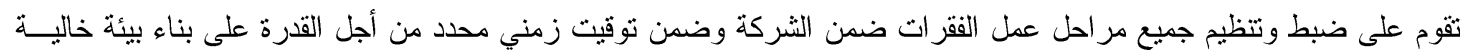

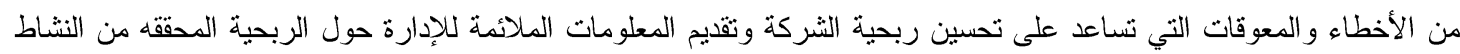

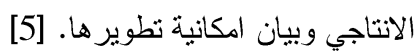

1-3 أنواع القيود:

ف6 المشاريع الانشائية تقسم القيود الى خمسة أنواع هي [6]

1.قيود تكنولوجية(فنية): تشمل جميع ما يتعلق بفقرات العمل الخاصة بالمشروع وكيفية نتفيذ تلك الفقرات وفق ما يتطلب من تجهيز فنيين ومعدات وأيادي عامله ومواد انشائية لها، إذ أن اي تقصير او خلل في التجهيز يؤدي الى تأخير العمل ومن ثم ثن يصبح قيد يتطلب معالجته لغرض الاستمرار بالعمل.

2.قيود اقتصادية: تثمل كل ما يتعلق بنفقات المشروع المخصص لها واستلامها على شكل دفعات من الجهة المموله للمشروع وحسب ما هو متفق عليه بين الشركه وتللك الجهة، إذ أن أي خلل في تسليم النقات يؤدي إلى توقف العمل ويصبح ذلك قيد اقتصادي من الضروري معالجته.

3. قيود بيئية: يتعلق هذا النوع من القيود بطييعة المنطقة المحيطة بالمشروع الانثائي ومايحاديها من معوقات بيئية تمنع أو

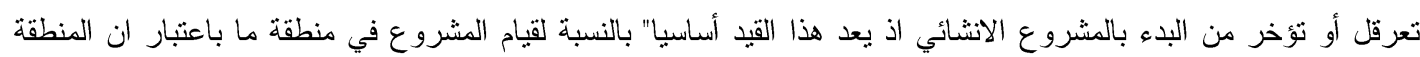

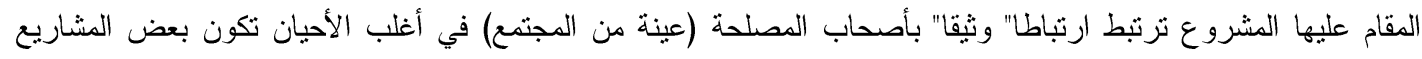
المقامة لا تتتاسب مع الواقع البيئي، لذلك قد تضطر الدولة في بعض الاحيان الى تغير موقع المشروع او الغاءه أو معالجته تماثيا" مع ما يملي عليهم من قرار بيئي.

4. قيود قانونية: تتعلق بكيفية إستحصال الموافقات من الدوائر والاستملاكات لمنطقة العمل من حيث الأرض المقام عليها

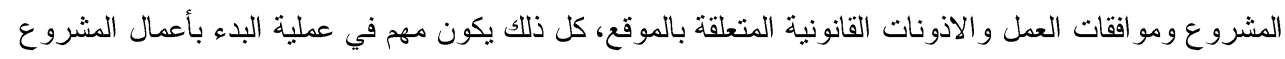
5. قيود سياسية: وتتمل كل ما يتعلق بأمن الدولة واستقرارها، إذا ان عدم الاستقرار الناحية الامنية يؤثز على جميع مفاصل الدولة بشكل كبير جدا" ويؤثز بشكل كبير على أغلب القيود التي ذكرت اعلاه. 


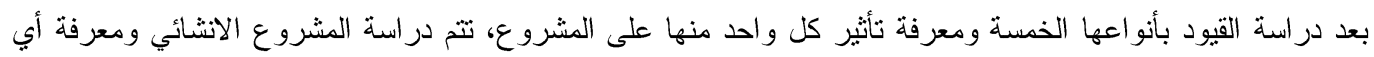

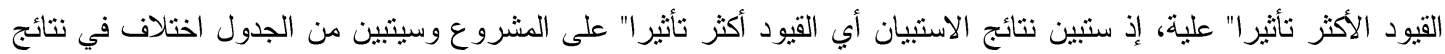

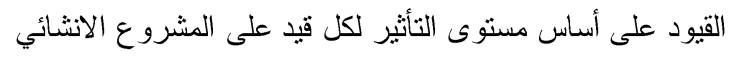

جلول (1) درجة مستوى الاهمية على المشروع الاشثائي

\begin{tabular}{|c|c|c|}
\hline درجة مستوى الاهمية على المشروع الآشائي & القيود & $ت$ \\
\hline & تكنولوجية & 1 \\
\hline & اقتصادية & 2 \\
\hline & بيئية & 3 \\
\hline & قانونية & 4 \\
\hline & سياسية & 5 \\
\hline
\end{tabular}

المصدر : من عمل الباحث

1-4 الخطوات الخمس لنظرية القيود

يوضح [7] أن أساس نظرية القيود هو التزكيز على عملية التحسين المستمر ، إذ لا تستطيع الثركات من أن تحقق أهـــافها

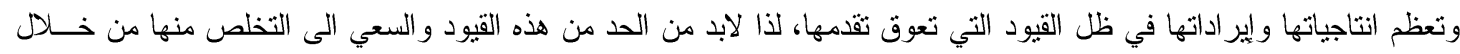
مجمو عة من الاجر اءات والخطو ات العملية نذكر منها:

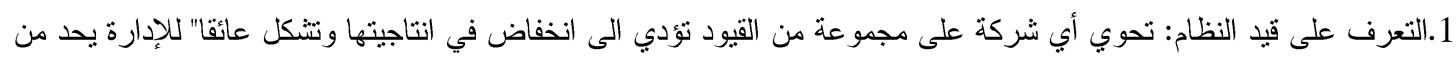

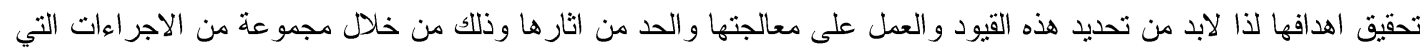

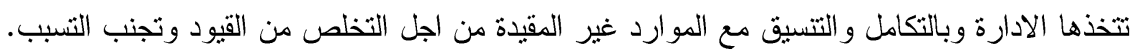

2.تحديد كيفية استغلال القيد: بعد تحديد القيد لابد من الاستفادة القصوى من مورد القيد والحد من اثاره السليبة والعمل على تحسينه

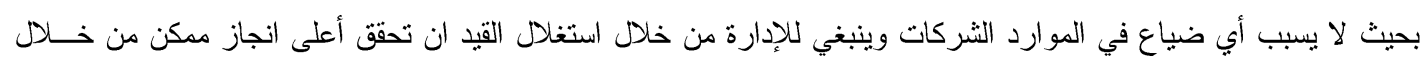

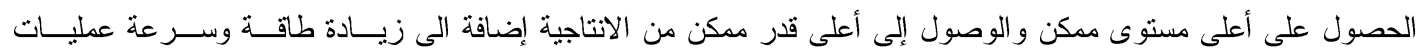
الشركات و التخلص من أي نوع من الاختناقات داخلها.

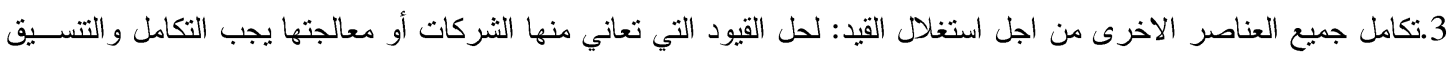

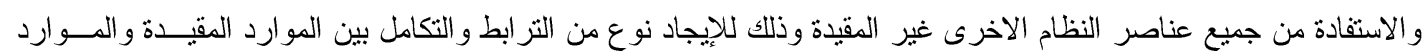
غير المقيدة و عدم التنبب بالاختناق بالنسبة للمو ارد الغير مقيدة ومن ثم تثكل قيدا" جديدا". 4.رفع القيد (التخلص من القيد): من خلال مجموعة من الاجر اءات الكفيلة في إز الة القيود و التخلص منها و القيام بعمليات إضــفية تساعد على إز الة القيود ومن هذه الاجر اءات: أ. زيادة الطاقة الانتاجية للمورد المقيد ب. الاستفادة القصوى من المورد المقيد من خلال تدريب القائمين عليه وزيادة مهار اتهم 5.البحث عن قيود جديدة: معظم الثركات تعتمد على الانتاج بمر احل متعددة ومن ثم ينم التخلص من أحد القيود في إحدى فقــرات

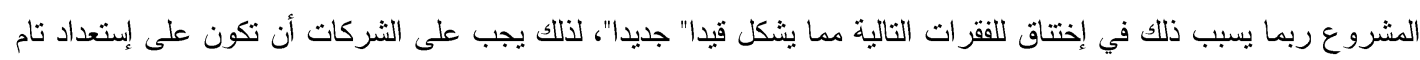
ل كعالجة القيود الجديدة وحلّها. 


\section{شكل (1) يوضح خطو ات نظرية القيود}

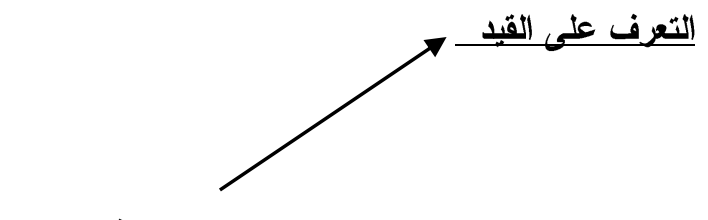

البحث عن قبد جدبد
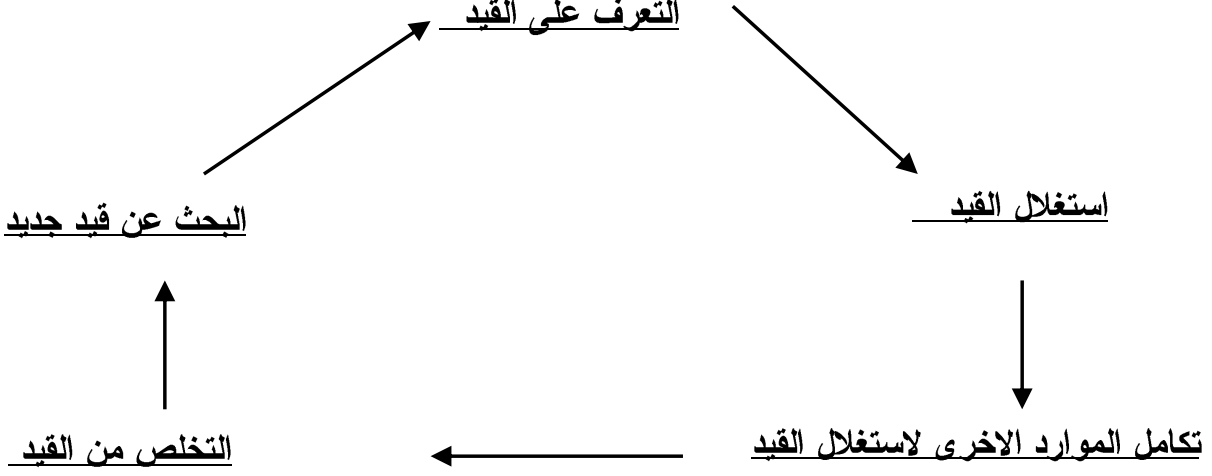

المصدر : من اعداد الباحث

2.مفهوم القبا:

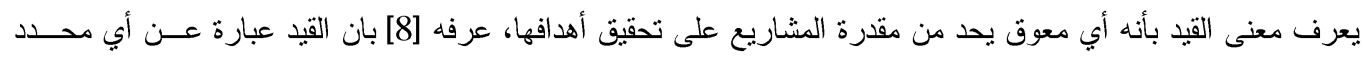

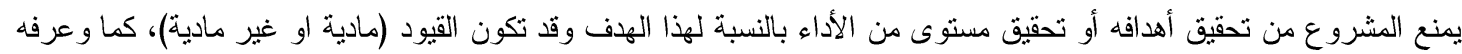

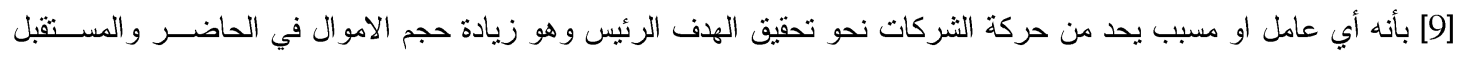

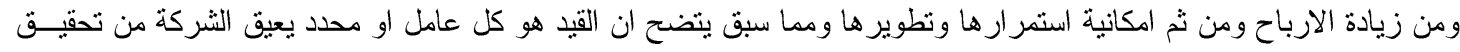

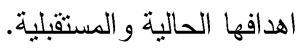

3.

لقد طورّ [10] منهج عام لتحديد القيود وخلق الحلول المتقدمة لها مستخدما" الحس المعرفي و المنطقي ويثــار الـى هــــا الاجر اء على انه عملية ألنفكير، كما يوضح [11] ان أدوات منهج التفكير ربما تكون أعظم الانجازات الفكرية وذلك ابتكار حسـاب التفاضل و التكامل. إن عملية التفكير صنفت بصورة مناسبة من خمس ادوات ذات اسلس منطقي ذلك انها تسمح للهـديرين بتحليـل

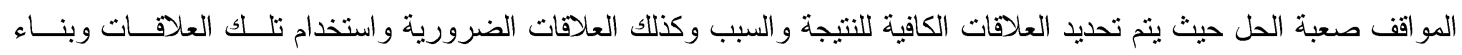
تمثيل بنائي للموقف و الحل الخاص به، فأدوات التفكير يمكن استخدامها في بيئة التصنيع و الخدمة وعلى المستوى المهني أيضــا،

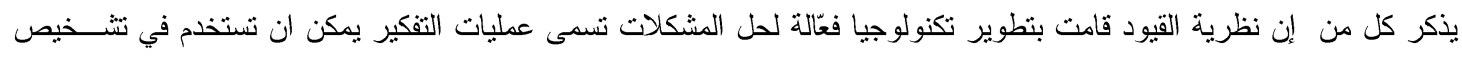

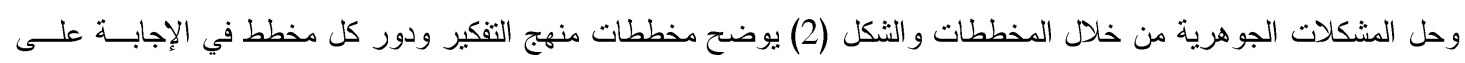
التساؤلات 
شكل (2) يوضح مخططات منهج التفكير ودور كل مخطط في الاجابة على التساؤلات

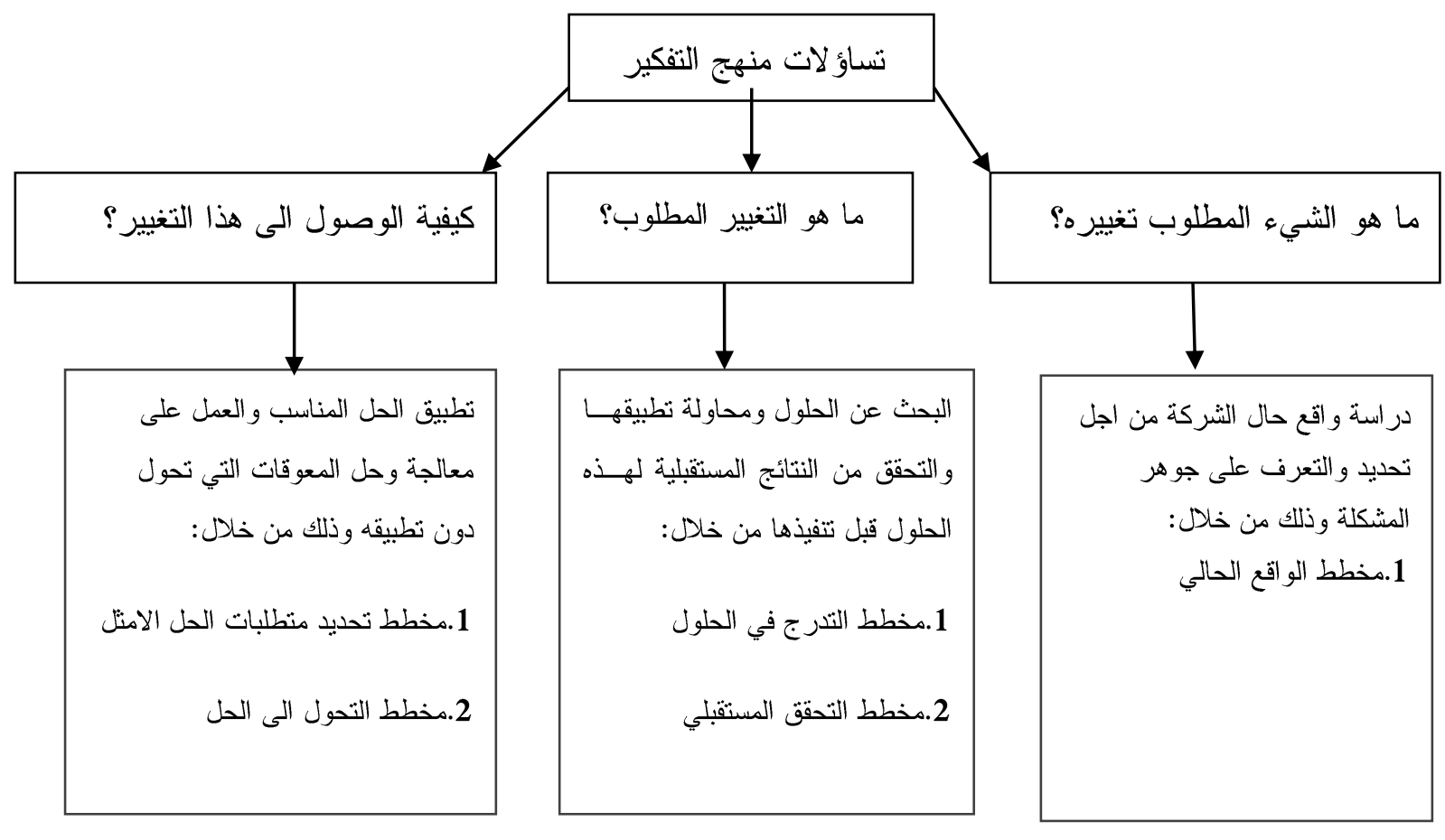

المصدر: من اعداد الباحث

1-3 أهمية منهج التفكير:

من خلال العرض السابق لمفاهيم منهج التفكير يلاحظ إنه يوفر اطارا" متكاملا" لإلية عمل المشاريع إذ يساعد على تحديــد ومعالجة المعوقات التي تعاني منها المشاريع و العمل على تحديد الحلول الملائمة وذلك من خلال مجمو عة من مخططــات التفكيـر المنطقية التي تبدأ بدر اسة واقع الحالي للثركة التي تعاني من المعوقات ومن ثم البحث عن مجموعة المعوقات التي تعانيهــا ويــتم تزتيب المعوقات بحسب أهميتها ومدى ارتباطها ببعض وذلك من اجل تحديد المشاكل الجوهرية التي تسبب في حدوث الو اقع غيـر المرغوب ، يتم بعد ذلك تقديم مجموعة من الحلول المقترحة ويتم در اسة هذه الحلول وبيان النتائج المستقبلية لكل حل وفائدتــه فــي معالجة المشكلة المحددة ومدى الاثر المستقبلي لتطبيقه ، بعد تحديد منطلبات كل حل من هذه الحلول من أجل خلق واقع جديد لعمل الثركة عكس الو اقع الحالي ومما سبق يمكن تفسير منهج التفكير بأنه يثكل اطر متكاملة لتحديد ومعالجة المعوقات التي تعاني منها الثركة و الارتقاء بها الى مستوى أعلى و أفضل في الانتاج و الربح.

\section{4. التقييم الميداني لدرجات الاهمية على مستوى ديوان محافظة بابل:}

يتم استعر اض لمحة عن كيفية عمل الثركات المنفذة للششاريع الانثائية و أساليب التعامل معها من قبل الكوادر المشرفة أو

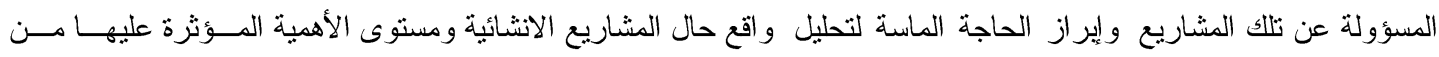
الناحية(الاقتصادية، الفنية،البيئية، القانونيه و السياسية) في المشروع الانشائي و إمكانية تطبيق الجوانـب النتظيميـة و التخطيطبـة و التتفيذية بالاعتماد على المنهج الميداني في التحليل وباستخدام اسلوبي الاستيبان و المقابلات الثخصية لغرض الوقوف علـى اراء المتخصصين في تقييمهر لدرجات الأهمية. 


\section{4-1 أسلوب الاستبيان:}

إن الوقوف على آر اء المتخصصين في موضوع تقييم واقع ومستوى درجات الأهمية في المشاريع الانشائية تحنل اهميــة اساسية في تعزيز و اقع وسبل تحقيق أهداف المشاريع الانشائية من خلال جمع آر اء اصحاب الرأي، وبهدف التوصــل الــى هـــه الار اء كان لابد من اجر اء عملي يعتمد اسلوب الاستمارة الاستيانية يتم توزيعها على المتخصصين للوصول الى هذه الاهداف، فقد اعتمدت على افكار وفرضيات أسلوب (Karin) ومسوّغات ذلك استتدت الى شمولية هذا الاسلوب منهج عملــي لتقيــيم مســتوى

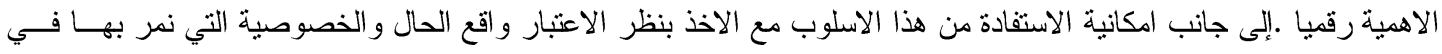
الوقت الحاضر ، من ناحية تتفيذ المشاريع الانشائية و الاستفادة من الايجابيات من الخبرات المنز اكمة لــدى المؤسســات و الجهــات المعنية وبعد الدر اسة استطعنا صياغة قسم من الاسئلة التخصصية التي تهتم بعمليتي (البعد التخطيطي و التتظيهـي وكـذلك البعـد

\section{اذذ تم تحدب الاسئلة على النحويين الاتبين:}

أ.تحديد درجة الاهمية في البعد التخطيطي والتنظيمي الخاصة بالمشاريع الانثائية.

ب. تحديد مستويات الاهمية رقميا بإبعادها التنفيذية .

أسلوب كاربن الاحصائي

ويتكون هذا المقياس عند (Karin) مما يأني

\begin{tabular}{|c|c|c|}
\hline درجتها & مستوى الاهمية & ت \\
\hline 5 & قوي & 1 \\
\hline 3 & متوسط & 2 \\
\hline 1 & ضعبف & 3 \\
\hline
\end{tabular}

من عمل الباحث

أما الأساس الذي يقوم عليه هذا التقسيم فيتمثل في تحديد الابعاد التخطيطية والتظظية وتفر عاتها الخاصة لكل أهمية التي يرتبط بها هذا المقياس وكذلك الابعاد التتفيذية وتفر عاتها وبعد ذلك ينم وضع المقياس من قبل نتائج الاستبيان او المقابلات الشخصية وكذلك مقياس من قبل الباحث وإجر اء المقارنة بينها لحين الوصول الى نتيجة في امكانية التطبيق أم لا وقد عمد الباحث لمقياس اخر وبرتب تصاعدية ثابتة ومحددة وذلك للتنبت من النتائج ومطابقتها مع المقياس المستخدم من قبل الباحث على النحو الآتي:

\begin{tabular}{|c|c|c|}
\hline درجتها & مستوى الاهمية & ت \\
\hline 3 & قوي & 1 \\
\hline 2 & متو سط & 2 \\
\hline 1 & ضعيف & 3 \\
\hline
\end{tabular}

من عمل الباحث 


\section{أ.تحديد درجة الاهمية في البعد التخطيطي و التتظيمي الخاصة بالمشاريع الانشائية}

لقد رتبت مستويات الاهمية بالمتغيرات الخاصة لكل درجة أهمية كما وردت الاجابة من الاستمارة الاستييانية عن ديوان محافظة بابل والجهات ذات العلاقة التابعة لها وذلك لأن هذه الدوائر تعد مختصة بالمشاريع ويمكن مقارنة الأعمال على باقي محافظات القطر وكانت حصيلة الاستبيان لكل درجة اهمية وفق ما تحويه من محاور وهي كالأتي:

من خلال هذه النتائج وبنطبيق هذا المقياس حصل البعد التتظيمي التخطيطي المحددة والمرتبطة بدرجة الاهمية على معدل للمستوى الاقتصادي (3) حسب درجة الاستييان وبمعدل(2) درجة بمقياس الباحث بينما كان المعدل على المستوى الفني (4) حسب درجة الاستيبان وبمعدل(2.6 ) درجة بمقياس الباحث وقد كانت نتيجة معدل المستوى البيئي (3 ) حسب درجة الاستبيان وبمعدل(2.4 ) درجة بمقياس الباحث بينما كان المعدل على المستوى القانوني (2.2 ) حسب درجة الاسنيان وبمعدل(3 ) درجة بمقياس الباحث وعلى المستوى السياسي (4.2 ) حسب درجة الاستبيان وبمعدل(3 ) درجة بمقياس الباحث هذه النتيجة تعطي مستوى لدرجة الاهمية فوق المتوسط ,نستتتج من ذلك وجود الامكانية الكافية لتطبيق البعد التنظيمي التخطيطي اذ انها تمكن من الاعداد و التتفيذ والمتابعة للمشاريع و لاسيما المشاريع الانثائية

$$
\text { ب استخدام التطبيقات الجاهزة برنامج SPSS - الاحصائي }
$$

ولأختبار النتائج التي حصلنا عليها على مسنوى الاهمية وإمكانية تطبيقها بمستوى فوق المتوسط على عموم، البعد التخطبطي و التظيمي استخدم الباحث البر امج التطبيقية الجاهزة الخاصة بهذه العملية و لاسيما برنامج(SPSS) الاحصائي للمقارنة أكانت هنالك فروقات جو هرية (معنوية) بين درجات ألاهمية أم لا؟

\section{1.اختبار Kruskal - Wallis للأبعاد التنظيمية و التخطيطية}

يعتمد هذا الاختبار على اسلوب (Non-Parametric Test) وذلك لأن هناك رثبا" رقمية خاصة لكل بعد تخطيطي،

$$
\text { وتتظيمي على مستوى الاهمية }
$$

$$
\begin{aligned}
& \text { وقد وضعت الفرضية من قبل الباحث لهذا الاختبار على وفق ما يأتي: } \\
& \text { عدم وجود تأثير أو فرق معنوي: } \\
& \text { وجود نأثير أو فرق معنوي: }
\end{aligned}
$$

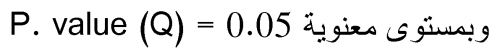

اي يسمح ب (5\%) مجال الخطأ في العينة المدروسة وبدرجة ثقة 95\%

$$
\text { Asymp. Sig }
$$$$
\text { وقد ظهرت النتائج كما في الجدول الآتي: }
$$

جدول (1) الاختبار الاحصائي (Test Statistics) للأبعاد التنظيمية والتخطيطية

\begin{tabular}{|c|c|c|}
\hline الاختبار & الدرجة & $ت$ \\
\hline Chi-Square & 1.963 & 1 \\
\hline df & 1 & 2 \\
\hline Asymp. Sig & 0.161 & 3 \\
\hline
\end{tabular}

المصدر : من اعداد الباحث 


$$
\text { (Asymp. Sig) = P. Value (Q) =0.161 القيمة التقريبية هي }
$$

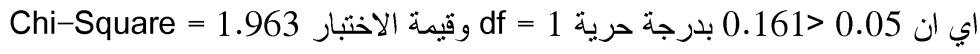

ومعنى ذلك نرفض الفرضية H للباحث .و نقبل فرضية الاختبار H اي انه لا توجد فروقات معنوية بين درجات الأهميــة

على مستوى البعد التخطيطي و التنظيمي و هذا يعطي بالنتيجة امكانية تطبيق هذا الاسلوب من التخطيط و التنظيم على عموم درجـات الأهمية، بل اعطي نوع من الموازنة ما بينهما بالنسبة لباقي درجات الاهمية التي تبدي الاستعداد الكامل لاتخاذ القرار بدرجة أهمية

\section{2. تحدبـ مستويات الاهمبة رقمبا بإبعادها التتفيذبة:}

تحديد مستويات الاهمية على درجاتها رقميا" في مجال إقتر اح ومتابعة تتفيذ المشاريع الانثائية بالارتبـاط بالتخصــيص،

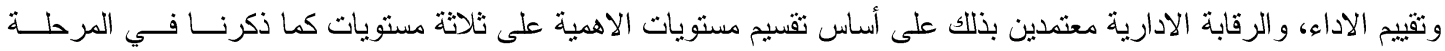
الأولى وقد حددت الابعاد التنفيذية وأعطيت الرموز الخاصة بها وبموجب تسلسل مر احلها و على النحو الآتي:

$$
\begin{aligned}
& \text { 1. ـ الاقتراح } \\
& \text { 2. اعداد وتتفيذ الخطط الخط } \\
& \text { 3. التخصيص } \\
& \text { 4. تقيبيم الاداء } \\
& \text { 5. الرقابة }
\end{aligned}
$$

ولتطبيق هذا الاسلوب على نتائج الاسنيان نم اختيار الاسئلة الخاصة بهذا المجال من بين اسئلة استمارة الاسنيبان، وهي

$$
\text { الاسئلة () وقد اعطيت مقياس تز اتبي تصاعدي ثابت لقياس مستوى ودرجة الاهمية وكما يلي: }
$$

من خلال هذه النتائج وبتطبيق هذا المقياس حصل البعد التتفيذي المحدد والمرتبط بدرجة الأهمية على معدل لمستوى الاهمية الاقتصادية (3 ) حسب درجة الاستبيان و بمعدل(2 ) درجة بمقياس الباحث اما على المستوى الفني فثث كانت(4.2) حسب بلت درجة الاستييان وبمعدل(2.6 ) درجة بمقياس الباحث وبينما كانت على المستوى البيئي (3.4 ) حسب درجة الاستييان وبمعدل(2.2 ) درجة بمقياس الباحث و على المستوى القانوني (2.6) حسب درجة الاستييان وبمعدل(2.4 ) درجة بمقياس الباحث و على المستوى السياسي (2.6) حسب درجة الاسنبيان وبمعدل(2.4 ) درجة بمقياس الباحث ويعد هذا المستوى جيدا في المرحلة الراهنة اي ان هناك استعداد او امكانية لتطبيق درجات الاهمية على المستوى التتفيذي وبدرجة فوق المتوسط، وان بإمكان المستويات المقترحة تكون مناسبة في اعداد وتتفيذ هذه المشاريع· إن هذه النتيجة تعطي مستوى لارجة الأهمية فوق المنوسط، نستتنج من ذلك وجود الامكانية الكافية لتطبيق البعد التنفيذي بدرجة فوق المتوسط. ولاخنبار النتائج التي حصلنا عليها لمستوى الاهمية في البعد التتفيذي استخدمنا كما في المرحلة الأولى البرامج التطبيقية الجاهزة برنامج (SPSS) الاحصائي لمقارنة فيما إذا كان هناك فروقات جوهرية بين درجات الأهمية وإمكانية تطبيق هذا على باقي المستويات.

\section{أ.اختبار Kruskal - Wallis للأبعاد التنفيذبة}

قد حدنا في هذا الاختبار الابعاد التتفيذية الخمسة وعلى مستوى الاهمية وذلك لأننا اعتمدنا المستوى التتفيذي .وكانت الفرضية وقد وضعت الفرضية من الباحث لهذا الاختبار على وفق ما يأني: وقد ظهرت النتائج كما في الجدول الآتي: 
جدول (2) الاختبار الاحصائي(Test Statistics) للابعاد التنفيذية

\begin{tabular}{|c|c|c|}
\hline الاختبار & الدرجة & ت \\
\hline Chi-Square & 6.4 & 1 \\
\hline df & 1 & 2 \\
\hline Asymp. Sig & 0.011 & 3 \\
\hline
\end{tabular}

المصدر: من اعداد الباحث

نلاحظ من الجدول إن قيمة Chi-Square=6.4 وهي قيمة الاختبار المرتبط باختبار Kruskal الذي يعطي نتائج

الفروقات أ معنوية أم لا؟ وكانت قيمة مستوى المعنوية القيمة النقريبية Asymp. Sig =0.011 اي انها اصغر من مستوى المعنوية للاختبار 0.05 > 0.011 0.بدرجة حرية = df ومعنى ذلك نرفض فرضية العدم H0 للاختبار ونقبل الفرضية البديلة اي فرضية الباحث، اي انه يوجد هنالك فروقات جوهرية (معنوية) بين المستويات بونبحث عن مصدر آخر بين المستويات من خلال

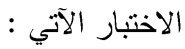

ب. باخ (KOLMOGOROV-SMI RNOVZ) يعتمد هذا الاختبار على اسلوب الفرضية البديلة وذلك بعد ظهور فروقات معنوية بين المتغير ات للعينة، وبالأسلوب نفســـ نضع الفرضية الخاصة لهذا الاختبار وقد ظهرت النتائج كما في الجدول الآتي: جدول (3) الاختبار الاحصائي (Test Statistics) للأبعاد التنظيمية والتخطيطية

\begin{tabular}{|c|c|c|}
\hline & ت الارجة & \\
\hline Asymp. Sig & 0.082 & 1 \\
\hline
\end{tabular}

القيمة التقريبية هي Asymp. Sig =0.082 اي ان 0.05 >0.082 ومعنى ذلك نرفض الفرضية H1 HO للباحث .ونقبـل فرضية الاختبار H0 اي انه لا توجد فروقات معنوية بين درجات الأهمية على مستوى البعد التتفيذي وهذا يعطي بالنتيجة امكانية تطبيق هذا الاسلوب على عموم درجات الاهمية. ج. المرحلة الثالثه

(Correlation Coefficient) استخدام معامل الارثباط)

تكون هذه المرحلة مرتبطة بالمرحلة الثانية ولاسيما في ابعادها التنفيذية في المستويات الخمسة مستويات قبد الدرس روبمــا

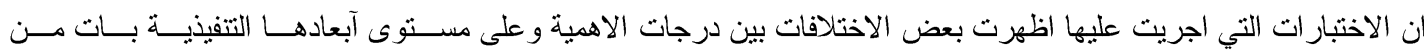
الضروري اجر اء الاختبار ات اللازمة بين هذه في هذه المرحلة وذلك لمعرفة مدى الارتباط والعلاقة فيما بينهم والتي أدت غلـى التى التى

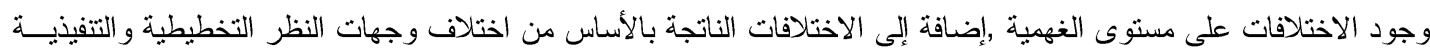

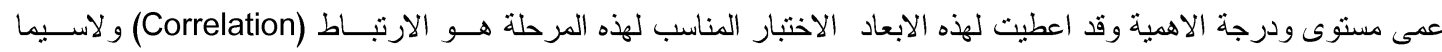

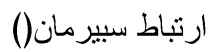

H0: rho = عدم وجود علاقة او ارتباط 0 وجود علاقة او ارتباط 0 fho 0 وبدرجة معنوية 
جدول (4) الاختبار الاحصائي (Test Statistics) للأبعاد التنظيمية و التخطيطية

\begin{tabular}{|c|c|c|}
\hline الاختبار & الإرجة & \\
\hline Correlation Coefficient. rho & 0.368 & 1 \\
\hline Asymp. Sig & 0.542 & 2 \\
\hline
\end{tabular}

المصدر: من اعداد الباحث

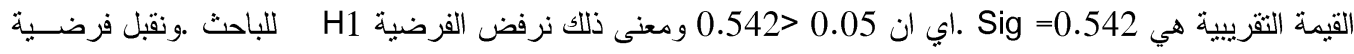

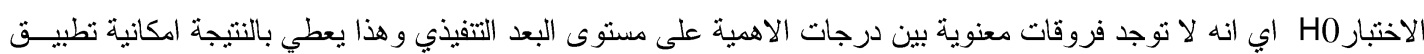

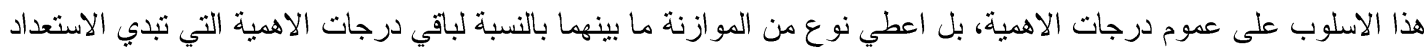

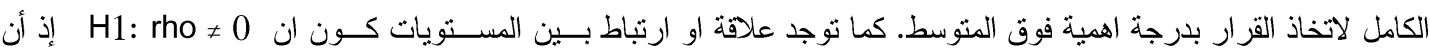

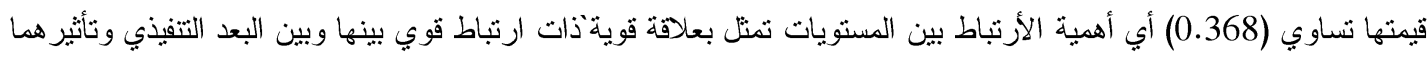
في بعضهما من الناحية العملية التطبيقية كو اقع حال.

5.مخططات منهج التفكير

اذ سنتطرق الى وضع حلول على شكل مخططات تفصيلية لحل القيود التي تو اجه المشاريع الانشائية، اذ تبدأ هـــه الحســول

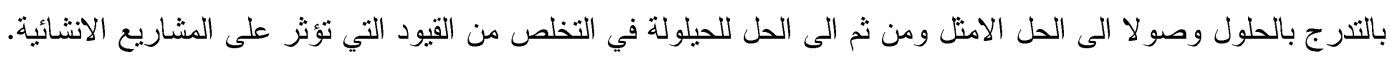

\section{5-1-1 بناء مخطط التّرج في الحول}

يفترض مخطط التذرج في الحلول أب حل يتضمن كحد أدنى خمسة عناصر منمثلة في الهدف المطلوب تحقيقه واحتياجين أساسيين يعتبر ان شرطان من أجل تحقيق الهدف وشرطين أساسيين يعتبران مطلبين لتحقيق الاحتياجات حيث تتم قراءة المخطط من

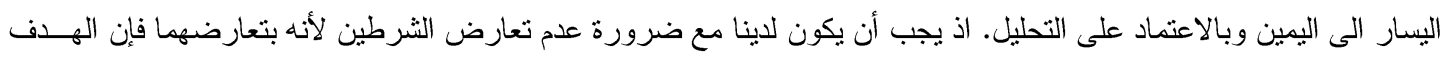

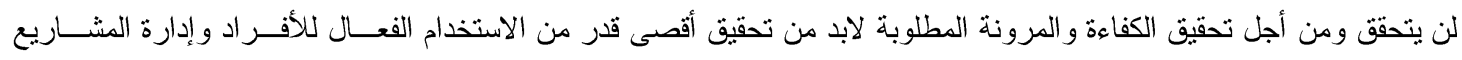

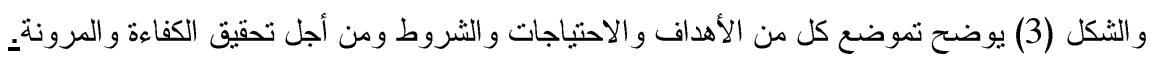

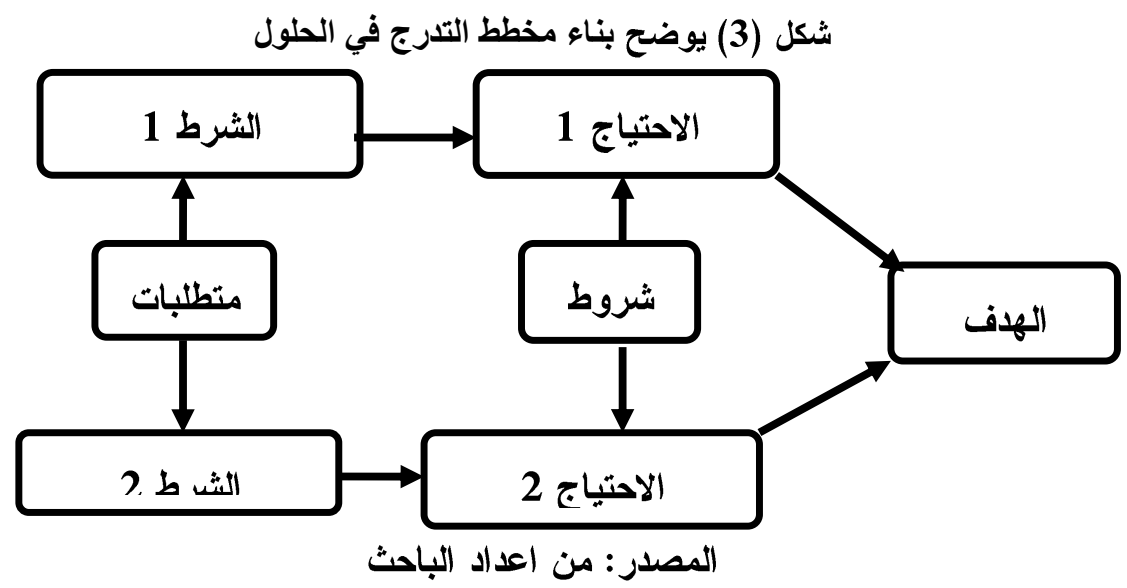

اذ سيتم تطبيق منهج التفكير من خلال المخططات الخاصة بها وبعد استعر اض مخطط واقع الحال في الفصل الثالث سوف يتم الان بيان مخطط التدرج بالحلول لحل القيود التي تشبب المعوقات في المشاريع الانشائية. 


\section{5-20ناء مخطط التحقق المستقبلي:}

مخطط التحقق المستقبلي هو تحويل لمخطط الو اقع الحالي للوقائع و الأحداث التي من شأنها أن تكون السبب في المشـكلة

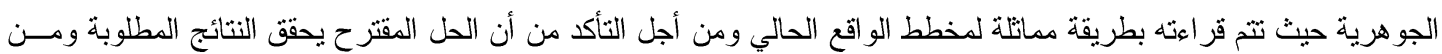

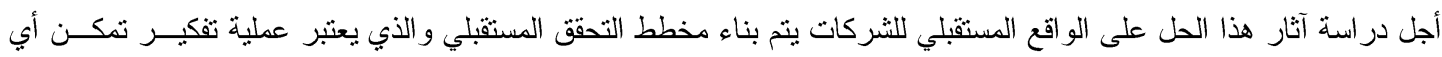

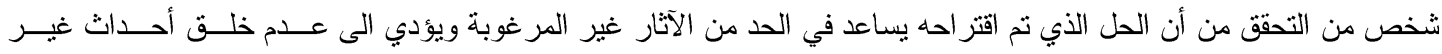

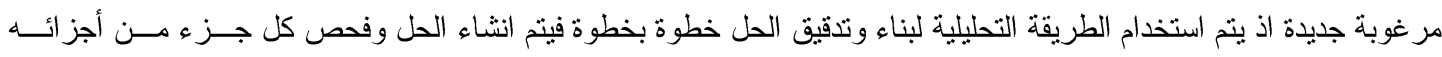

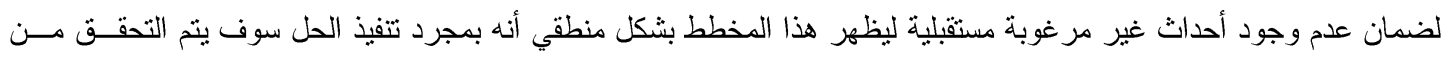

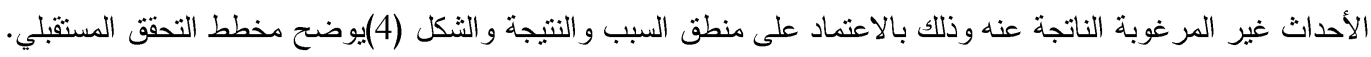
شكل (4) يوضح مخطط التحقى المستقبلي

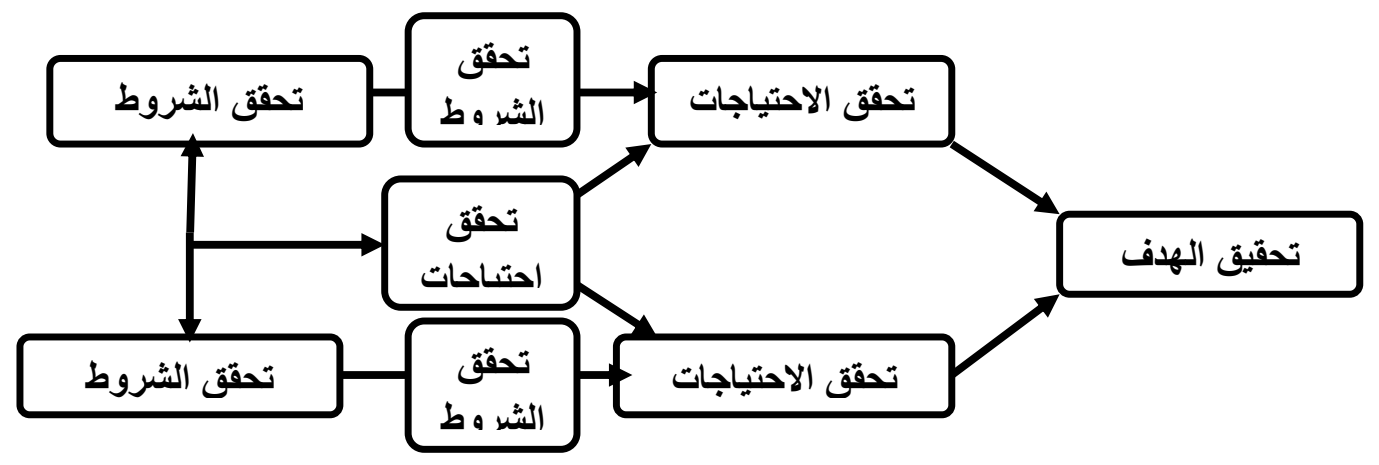

المصدر: من اعداد الباحث

5-3. مخطط تحليل المتطلبات الى الحل الامثل: يتم تحديد الأهداف المرحلية الو اجب تتفيذها وتحديد العقبات التي تحول دون تحقيق كل هدف و العمل على معالجتها. الثكل (5) يوضح مخطط تحديد متطلبات الحل الامثل

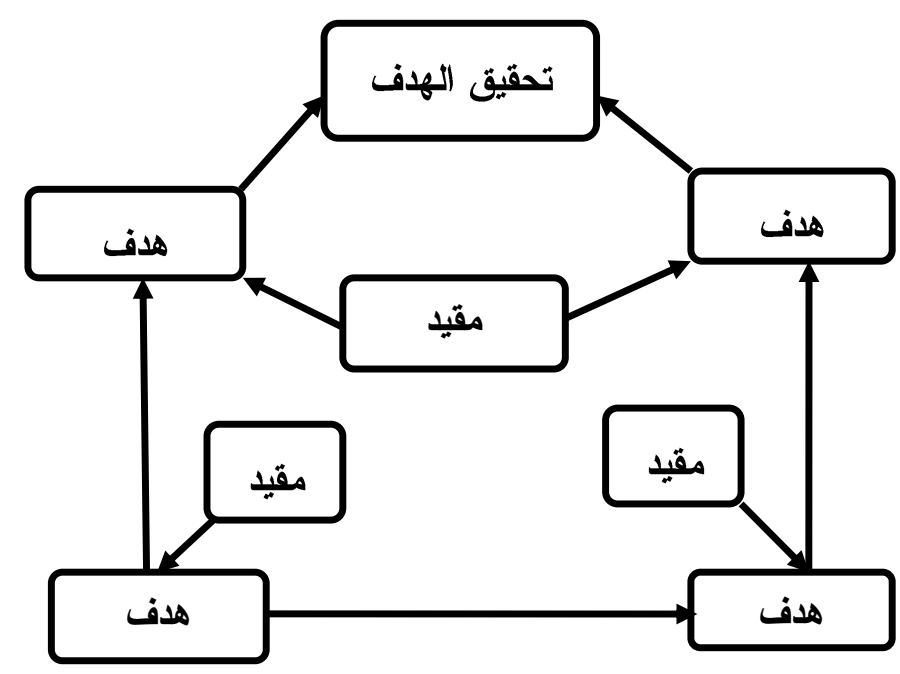

المصدر: من اعداد الباحث 


\section{5-4 - 5 5 5طط التحول الى الحل:}

ان هذا المخطط يحدد أن كل هدف نسعى الى تحقيقه وله سبب منطقي وحاجة لتحقيقه وهناك مجموعة من الإجر اءات التي

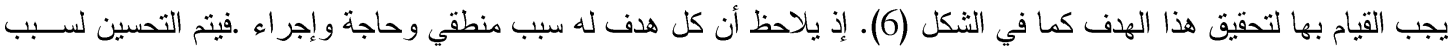
منطقي وهو ايجاد الحلول النهائية وذلك من أجل" النخلص من القيود بشكل نهائي "ويلاحظ أن كل هدف فرعي يعتبر احتياج لهدف لهان أخر مرتبط معه فتحسين كفاءة العاملين يعتبر احتياج أساسي لتحقيق القدرة على الاستغلال الأمتل للمواد الأولية. الثكل (6) يوضح مخطط التحول الى الحل

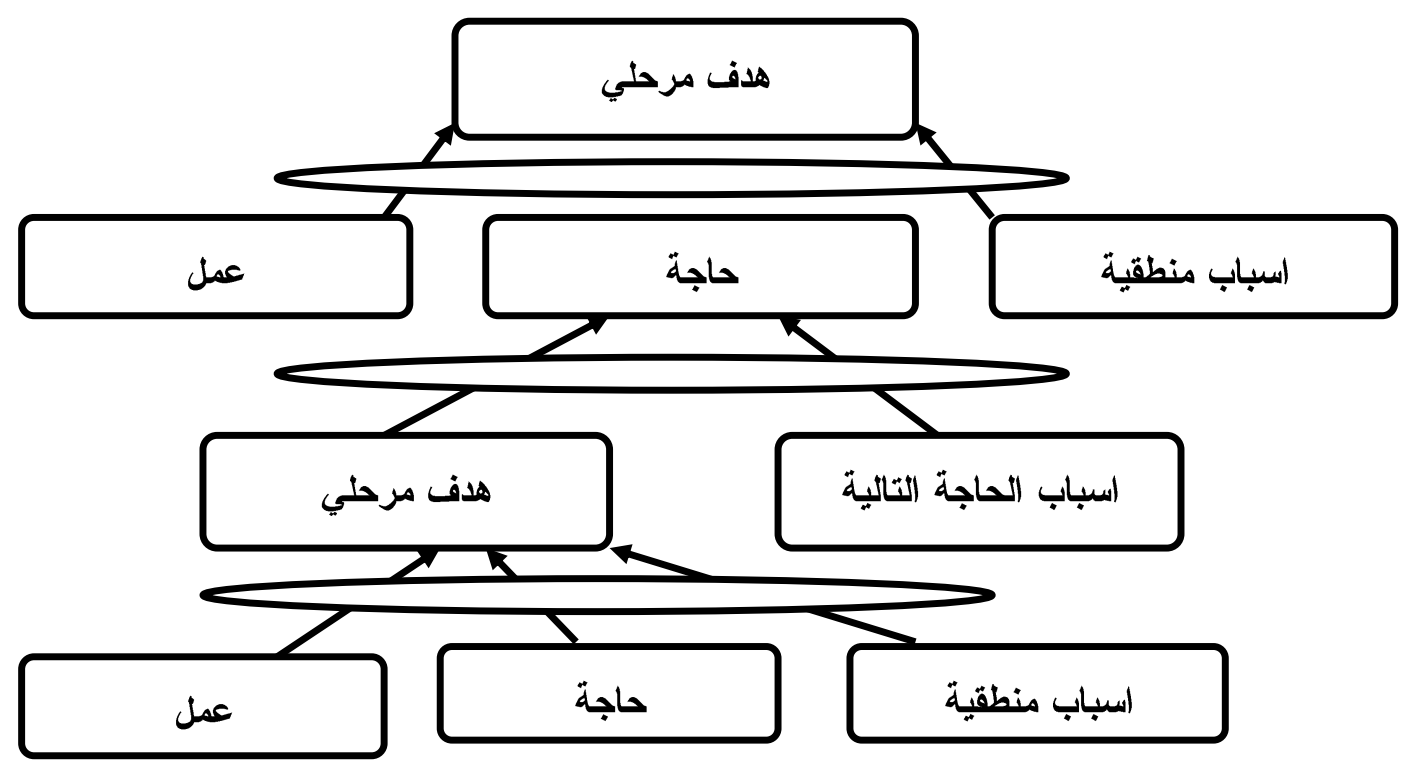

المصدر: من اعداد الباحث

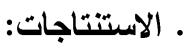

تمكنت الدر اسة من الوصول الى الاستتناجات التالية:

1. المتابعة الجيدة والإشر اف المستمر على المشروع له أثر كيير على سير نتفيذ المشاريع الانشائية بصورة جيدة ومنتاسقة. 2. إن الحاجة إلى كوادر إدارية وهندسية ذات خبرة في مجال تخمين الأسعار يجنب تأخر انجاز المشاريع. 3. قلة الخبرة الكافئة في إعداد خطة المشروع من حيث عدم الفهم الجيد لطييعة المشروع الهندسي وعدم القدرة على تحديد أهدافه

كذلك قلة الخبرة في وضع الجدول الزمني لنتفيذ المشروع وسوء تقدير الكلفة الفعلية له من خلال عدم اعتماد انظمة جيدة. 4. عدم جهوزية المكائن او المعدات المستخدمة في المشاريع الانشائية وكثرة التوقفات خلال تتفيذ المشروع بسبب عطلها او ما تلحقه من تلوث بيئي له أثز كبير على عمل المشروع ومن ثم يتأخر وقت المشروع. 5. تردي الوضع الأمني في البلد إذ له الدور الاساسي في تأخير إنجاز المشاريع بشكل عام وتوقفها في كثير من الاحيان.

6. تقدم نظرية القيود نتائج تفصيلية عن ماهية القيود المسببة في تأخر او تلكؤ او سبب انخفاض اداء المشاريع الانشائية. 7. ساعدت نظرية القيود ومنهج التفكير بتكاملهما معا" على القيود المسبية في تأخر المشاريع الانثائية، كما وقدم منهج التفكير الحلول الملائمة التي تساعد على التخلص من تلك المعوقات من خلال اعطاء حلول عدة الى حين الوصول الى الحل المطلوب. 
8. توضح الدراسة ان منهجية نظرية القيود التي تتمنل في عملية نركيز الخطوات الخمس هي ذات تطبيق مناسب في معظم عناصر ها التفصيلية ومعرفة مدى تأثنير القيود على المشاريع الانثائية. 9. اثثتت عطليات منهج التفكير ان عدم تطبيقها بالثكل المناسب يؤدي الى عدم تحديد المشكلات الجوهرية وكذلك الى عدم تحديد ادوات و أهداف التغيير مما يؤدي الى عدم ايجاد التظور في الحلول و الوصول الى الحل الو اقعي والأفضل.

7.

من خلال الاستتتاجات السابقة وما تضمنته الدر اسة تم التوصل إلى التوصيات الآتية:

1 ــمن الضروري ان يعالج الضعف الموجود في كفاءة كو ادر المشاريع الهندسية لعملية تخطيط المشروع وربـــ جو انبــهـ كــل، و إعداد كو ادر تدرييية كي تكتسب الخبرة والمعرفة بمجال المشاريع الانشائية من حيث التخطيط و التنظيم والتنفيذ. 2.ضرورة اعداد كو ادر مختصة بتخمين المشاريع الانشائية.

3.ضرورة التأكد من سلامة المكائن و المعدات من الناحية العملية و الييائية للمحافظة على سلامة الكوادر وسـير العهـل بصــورة

4. اتباع بر امج لتطوير مهار ات الكوادر الفنية وخبر اتهم العلمية والعملية وذلك من أجل السيطرة على كل المعوقات التـي تتـتج خلال مرحلة التخطيط و التنفيذ.

5.من الضروري تطبيق منهج التفكير في المشاريع الانثائية كنظام إداري ومن أجل تحديد القيود و المعوقات التي تعاني منها تلــــك المشاريع و العمل على معالجتها من خلال مجموعة مخططات التفكير المنطقي التي يقدمها كما و إنها توفر الية مناسبة في تطوير

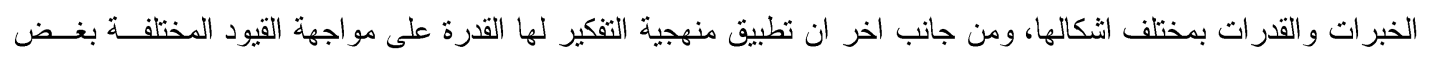
النظر عن ماهية ثلك القيود. 6.رفع كفاءة الأداء في مجال التخطيط و النتفيذ في المشاريع الانشائية. 7 . العمل على توسيع الصلاحيات للمشاريع الانثائية وذلك عن طريق رفدها بكل المقومات الضرورية بما فيها المساعدات المالية للوصول التدريجي المبرمج الى وضع الاستقلالية وتطبيق سياسة العدالة في التوزيع عند تتفيذ المشاريع المهمة. 8.تفعيل اليات الاستثمار في المشاريع الانثائية من خلال التتسيق مع وزارة المالية من جهة ومن جهة اخرى تتظيم العلاقة مـع القطاع الخاص لنتشيط دوره في العملية الاستثمارية.

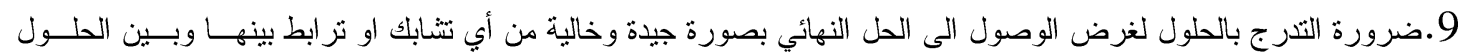
السابقة

\section{CONFLICT OF INTERESTS.}

- There are no conflicts of interest.

[1] تاتفي، أحمد " دور نظرية القيود في الرقابة على تكلفة المخزون و أثزرها على تخفيض تكلفة الإنتاج " رسالة دكتور اه غير منشورة، كلية الاقتصاد، جامعة حلب، 2001 [2] مؤنة، هبة محمود"مدى فعالية المحاسبة عن الإنجاز في ضوء مستجدات بيئة التصنيع الحديثة" رسالة ماجستير غير منشورة، جامعة الملك عبد العزيز ، السعودية،2004 
[3] كرول ابريل، واخرون "دور نظرية القيود على اداء المشاريع الانتاجية " دراسة علمية وبحثية، جامعة مينتيغن، امريكا

[4]Heizer. Jay, Barry. Render"Operations Management" Pearson Prentice Hall, Edition: 9 Th ed, EWU Library, East West University, Chicago, 2000

[5].mekoning capital " An Activity Based Costing and Theory of Constraints Model for Product Mix Decisions", Unpublished PHD Dissertation, Virginia University,2000

[6] الوضاح، محمد علي جلال" مشكلات القيود و إعادة هيكلتها في الثركات"، جامعة عين شمس، مطبعة الاهرام، مصر

[7] كولدرات، الياهو "الهدف " الطبعة الثالثة، مطبعة الصحافة النهرية، امريكا، 1990

[8] شو ، اليخانرو جيسز "ماهية القيود وماهية الثروط في التخطيط ودر اسة الجدوى" جامعة اوتاو ا، الطبعة الثانية، كندا، 2006

[9] كولدرات، الياهو "نظرية القيود" الطبعة الاولى، مطبعة الصحافة النهرية، امريكا، 1984

[10] نورين واخرون " التكامل ما بين نظرية القيود و الدور في تحسين الاداء" مجلة كلية الهندسة للبحوث العلمية، كلية الهندسة، جامعة الاسكندرية، مصر، 2008

[11] Perkins D., Stewart J," Using Excel, TOC, and ABC to Solve Product Mix Decisions with More Than One Constraint", Management Accounting Quarterly, 2002. 